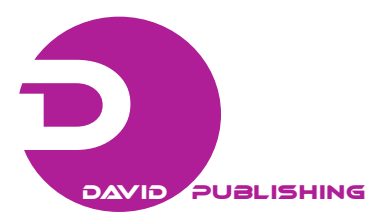

\title{
Residents' Satisfaction with the Public Housing Unit Features and Its Implications in China
}

\author{
Zhubin $\mathrm{Li}^{1}$, Tsuyoshi Setoguchi ${ }^{1}$ and Ke Huo ${ }^{2}$ \\ 1. Graduate School of Engineering, Hokkaido University, Sapporo 060-8628, Japan \\ 2. Department of Architecture, Northeastern University, Shenyang 110-819, China
}

\begin{abstract}
This paper studied the residents' level of satisfaction in public housing units in Shenyang of China which aimed to identify how each housing unit feature correlates with the residents' overall satisfaction and implication on policy and design. The discussion is based on a questionnaire survey conducted in 2011. This research concluded that more residents were satisfied with the housing unit features than those who were dissatisfied, while some remarkable differences could be observed if comparative analysis between two different public housing types in China were studied. The affordable housing residents are generally more satisfied with housing unit features than those living in low-rent housing. The most dissatisfying feature is the living room, followed by unit size and the floor plan. Additionally, the living room and the floor plans were features which were highly and positively correlated to the residents' overall satisfaction of housing unit features. Consequently, improving the living room size and the design of housing unit floor plans would clearly be beneficial to alleviating residents' dissatisfaction to the housing units.
\end{abstract}

Key words: Residents’ satisfaction, housing unit features, public housing.

\section{Introduction}

With the rapid economic development, property rates of commercial housing in China are soaring at an incredible rate, which have exceeded the affordability margin of the majority of people. In the long period after 1998, Chinese policy makers believed that the urban housing market, in the form of responsive housing provision has been viewed as a major dynamic of economic growth in China [1]. Nevertheless, urban housing prices were increasing faster under this perception of urban housing market and the Chinese central government had to improve the situation using its political power. In the recent years, the focus of the Chinese government was to curb the sharply increasing property rates and stabilize the housing market. The provision for public housing construction is therefore an important measure to relieve the burden of housing purchase on low and medium income groups, a relatively common focus

Corresponding author: Zhubin $\mathrm{Li}$, Dr. student, research fields: Chinese public housing design and residential satisfaction. E-mail: lizhubin128@gmail.com. both on the government and the public. Public housing policies, which were ignored originally by most policy makers [1], have been attracting more and more political and public attention. According to the Twelfth Five-Year Guideline of China, the government intends to provide 36 million public housing units for low and medium income groups by 2015, which represent $20 \%$ of total city housing units. This data reflects on the one hand the determination of Chinese central government to solve the housing problems of low-income people, and on the other hand, the urgency in public housing provision in part. China has a specific aim on public housing provision in the near five years. However, serious questions are still unanswered: "How to achieve the aim”, and "Will just increasing the public housing provision utterly solve the housing problems of low-income people”.

Politically, China has established a relatively fledged public housing system after a series of housing marketization reforms from 1998, which are viewed as the beginning of establishment of market-oriented housing system [2]. Initially, two 
public housing types: the affordable housing and the low-rent housing, were designed to target the medium income and low-income people, respectively. Affordable housing has some attributes to commercial housing to some extent, which was jointly developed by private real estate developers and local governments. Residents can obtain a public housing unit with partial property rights at an affordable rate and cannot exchange unless he/she obtains the full property rights through an additional payment. As the major public housing provision at the beginning phase of the new housing policies, affordable housing was surrounded by a lot of controversy over the effect of policy implementation and equality. On the one hand, some scholars admitted there was a positive effect on enlarging housing provision and catering for the accommodation of some medium income people $[3,4]$. On the other hand, developing affordable housing projects had become the major cause to cheap city lots for private real estate developers, which had given a negative influence on commercial housing market and development [5]. Furthermore, a series of problems, such as the vague target groups and incomplete subsidy system, led to inequality access to affordable housing and poor management [6]. These drawbacks compel the governments to change the major provision of public housing from saleable affordable housing to rental public housing to avoid the intensification of conflicts. Accordingly, low-rent housing, which was originally neglected, gradually attracted more political attention. Nevertheless, the low-rent housing provision was inadequate in a long period of time. Its construction and maintenance could benefit much less fiscal revenue and was unhelpful for the government's course [7]. Other scholars also criticized the local governments for their dereliction of duty in public housing provision [8]. Consequently, some local governments began to reconsider their public housing system and attempt to make some changes. A new public housing type, public rental housing, was introduced into public housing system in
2010, which features a higher rent but a wider coverage. Public rental housing system was established based on the experience of relatively successful public housing construction in Hong Kong and Singapore [9]. Public rental housing is expected to be a major component for future programs which are still being developed.

Shenyang city, which is the largest city in northeastern China, was selected as the case study with a total population of 7.2 million. This local city was selected away from famous cities like Beijing and Shanghai, which had always been the center for policy and design implication studies that can also be applied to other larger cities. Comparative analyses between the metropolis and the local cities on public housing issues are also technically significant for a comprehensive solution to housing issues in Chinese cities.

\section{Overview of Previous Studies}

Chinese housing reform, in that public housing plays an important role, has always been a hot research topic [1, 2, 10]. The urban housing redevelopment was also frequently discussed by many researchers [11, 12]. These studies explored the roles of various factors, such as housing price, rural-urban migrants, finance and residential satisfaction, which presented valuable policy implications on urban housing reform. Nevertheless, physical environment like, building units and neighborhood facilities, are also relative to citizens' residential satisfaction in the public housing which had not attracted adequate concerns from Chinese researchers [13]. More specific studies are therefore required to answer questions like, "what does a "Housing” mean to low-income people", "what are their preferences and living styles", features believed to achieve a comprehensive solution to improve the residents' satisfaction in public housing.

Developed countries like UK and USA conduct regular survey on tenant satisfaction to collect information about public housing performance [14]. 
The residential satisfaction survey supplies an effective way to communicate with residents and adds a user perspective to the evaluations of public housing construction and design. Unlike China, where surveys are not regularly conducted, such valuable information is limited but now in demand in the recent years. In his study about affordable housing satisfaction in Beijing city, Li [6] considered the categories of the inadequate neighborhood facilities, remote project location, long commuting distance and poor public housing management as major factors which were important, but left out and that had led to the dissatisfaction. Chinese cities are undergoing massive transformation in appearance and structure in its recent economic boom. City redevelopment had caused residents to be displaced and relocated, where public housing becomes an important option for resettlement. Fang [11] and $\mathrm{Li}$ and Song [12] respectively took Beijing and Shanghai as case studies which, explored factors like residents' moving intention, moving behavior, housing conditions and residential satisfaction in the process of the city redevelopment. It was found that the unit size and the length of stay had a close relationship with the low level of satisfaction in Beijing [11]. This finding in part supported the notion of Kinsey and Lane [15], who suggested that more space in a dwelling contributed to a high level of satisfaction. However, unlike the low level of satisfaction in Beijing, the displaced residents in Shanghai were more satisfied with their housing conditions [12]. Also, the previous residential satisfaction studies have indicated that residential satisfaction is a complex construct, which may be affected by housing types, tenure, cultures, socio-demographic attributes, housing price and the length of residency $[16,17]$. Since there is no general theory of residential satisfaction available, researchers inclined to study this issue through a comparative or correlative approach. Vera-Toscano [18] studied "the relevance of social interactions on housing satisfaction" and Salleh [19] observed how the neighborhood factors affected residents’ satisfaction [19]. These studies explored how a specific variable correlates with residential satisfaction.

In this study, the authors try to focus on housing unit features, which refer to the unit size, floor plan, bathroom, toilet, etc.. They have been documented as important predictors of residential satisfaction. Mohit [17] in his study on newly designed low-cost public housing in Malaysia found housing unit features has high positive correlations with residential satisfaction. Salleh [19] also pointed out building features are strongly correlated with residential satisfaction. Furthermore, some micro-level studies on public housing design in China implied the housing interiors in public housing were of poor unit quality [20, 21]. Consequently, more studies on solutions to improve public housing unit features become pressing, such as the number of bedrooms, quality of housing unit, sizes of bathroom, which are closely related to residents' satisfaction with public housing in China.

\section{Research Objectives and Questions}

Researches on residential satisfaction are usually dominated by researchers from fields of sociology, economics or geography. To a certain extent, their findings are more inclined to administrative policy making than architects who need specific information to direct the design practice technically. The study on building unit features attempts to discuss residents' satisfaction with housing unit from a perspective of a design architect, not only on policy makers alone but also on the design behind residents' assessment of their housing units. These findings are supposed to be meaningful for the large-scale public housing construction in the near future in China. Based on this objective, this study tries to answer the following questions:

(1) Socio-geographic attributes: Who are living in Chinese public housing;

(2) Satisfaction: How do residents assess their housing unit features; 
(3) Correlation: How much each assessed unit feature influences the overall satisfaction;

(4) Solution: What are the policy and design implications of residents' satisfaction with each unit feature.

Considering that the public rental housing in China are mostly still under construction, the other two public housing types, namely, affordable housing and low-rent housing, would be the focus of this study. A comparative analysis on residents' socio-geographic attributes and their satisfaction with housing unit would be undertaken to determine if there are significant differences between them.

\section{Research Methodology}

Data used in this study was obtained by a questionnaire survey conducted in six public housing projects in Shenyang city. Questionnaires were designed based on the research questions, which consists of three components: The first is the residents' socio-geographic attributes, including age, family size and type, occupation, educational level, income, etc.; The second is residents' satisfaction with different housing unit features. According to Mohit [17], housing unit features mainly refer to housing layout and internal spaces distribution and their quality, including living room, dining, bedroom, kitchen, bathroom, toilet and drying areas and ventilation of the housing. Considering the cultural differences and living custom, we adjusted it to be congruent with the Chinese context. Dining and drying areas were not considered in this survey since they are usually designed within the kitchen and bathroom in Chinese housing unit. Bathrooms and toilets are usually located in the same space, thus, they were assessed as a single item; The third is the residents' subjective comment on housing unit features and their aspiration, which provides us with additional information to assess their satisfaction level.

The SPSS was used to do descriptive analyses about respondents' socio-geographic attributes and correlation analysis. Respondents were asked to describe their subjective perception of housing unit on the following levels of satisfaction: "very satisfied”, “satisfied”, “dissatisfied” and "very dissatisfied”. No neutral response was provided, since a forced-choice question has been documented to make the data more accurate [22]. The YIS (Yeh's index number of satisfaction) was used to estimate residents' satisfaction in each housing unit feature, which is written in the following Eq. (1):

$$
Y I S=(S-D) / R
$$

where, $S$ is the number of respondents that are very satisfied and satisfied with one variable, $D$ is the number of respondents dissatisfied and very dissatisfied with one variable and $R$ is the total number of respondents.

This index ranges from -1 to +1 . A larger index number indicates there are more respondents satisfied with one variable, conversely, a smaller index number indicates the dissatisfied respondents would be more. The absolute value of index number implies the degree of difference between satisfied and dissatisfied respondents.

\section{Results and Discussion}

\subsection{Respondents’ Socio-geographic Attributes}

The majority (which accounted for 56.3\%) in the current public housing residents were in the age range from 40 to 60 years old (Table 1). Around four-fifth (79.1\%) of householders were male. Most families (74.8\%) had two or three members, including couples and their children. Single person families (23.7\%) in low-rent housing were more common than those (9.5\%) in affordable housing. Many residents in low-rent housing had no job (41.7\%), or were retired (26.0\%), the retired and freelance worker accounted for $25.0 \%$ and $23.3 \%$ in the affordable housing respectively. Generally, residents living in public housing have lower literacy level. Around half of them (48.6\%) just finished junior high school 
Table 1 Demographic characteristics of the respondents in LH (low-rent housing) and AH (affordable housing) $(n=297)$.

\begin{tabular}{|c|c|c|c|c|c|c|}
\hline Characteristics & LH & $\mathrm{AH}$ & Total & LH (\%) & $\mathrm{AH}(\%)$ & Total (\%) \\
\hline \multicolumn{7}{|l|}{ Age } \\
\hline $20-29$ yr & 5 & 20 & 25 & 5.2 & 10.0 & 8.4 \\
\hline $30-39$ yr & 12 & 32 & 44 & 12.4 & 16.0 & 14.8 \\
\hline $40-49$ yr & 28 & 48 & 76 & 28.8 & 24.0 & 25.6 \\
\hline $50-59$ yr & 29 & 62 & 91 & 29.9 & 31.0 & 30.6 \\
\hline $60-69$ yr & 11 & 22 & 33 & 11.3 & 11.0 & 11.1 \\
\hline Over 70 yr & 12 & 16 & 28 & 12.4 & 8.0 & 9.4 \\
\hline Total & 97 & 200 & 297 & & & \\
\hline \multicolumn{7}{|l|}{ Gender } \\
\hline Male & 73 & 162 & 235 & 75.3 & 81.0 & 79.1 \\
\hline Female & 24 & 38 & 62 & 24.7 & 19.0 & 20.9 \\
\hline Total & 97 & 200 & 297 & & & \\
\hline \multicolumn{7}{|l|}{ Family type } \\
\hline Single person & 23 & 19 & 42 & 23.7 & 9.5 & 14.1 \\
\hline Couple only & 22 & 47 & 69 & 22.7 & 23.5 & 23.2 \\
\hline Couple living with their child & 23 & 91 & 114 & 23.7 & 45.5 & 38.4 \\
\hline Lone parent living with his/her child & 17 & 11 & 28 & 17.5 & 5.5 & 9.4 \\
\hline Couple living with their parents and child & 6 & 20 & 26 & 6.2 & 10.0 & 8.8 \\
\hline Other families & 6 & 12 & 18 & 6.2 & 6.0 & 6.1 \\
\hline Total & 97 & 200 & 297 & & & \\
\hline \multicolumn{7}{|l|}{ Family size } \\
\hline 1 member & 19 & 13 & 32 & 19.6 & 6.5 & 10.8 \\
\hline 2 members & 36 & 59 & 95 & 37.1 & 29.5 & 32.0 \\
\hline 3 members & 35 & 92 & 127 & 36.1 & 46.0 & 42.8 \\
\hline 4 members & 3 & 24 & 27 & 3.1 & 12.0 & 9.1 \\
\hline 5 members and more & 4 & 12 & 16 & 4.1 & 6.0 & 5.4 \\
\hline Total & 97 & 200 & 297 & & & \\
\hline \multicolumn{7}{|l|}{ Occupation } \\
\hline Worker in state-owned enterprises & 6 & 17 & 23 & 6.3 & 8.5 & 7.8 \\
\hline Worker in private enterprises & 7 & 40 & 47 & 7.3 & 20.0 & 15.9 \\
\hline Civil servant & 2 & 13 & 15 & 2.1 & 6.5 & 5.1 \\
\hline Freelance worker & 16 & 53 & 69 & 16.7 & 26.5 & 23.3 \\
\hline Retired worker & 25 & 49 & 74 & 26.0 & 24.5 & 25.0 \\
\hline Student & 0 & 1 & 1 & 0.0 & 0.5 & 0.3 \\
\hline No job & 40 & 27 & 67 & 41.7 & 13.5 & 22.6 \\
\hline Total & 96 & 200 & 296 & & & \\
\hline \multicolumn{7}{|l|}{ Educational level } \\
\hline Elementary school certificate & 5 & 9 & 14 & 5.2 & 4.5 & 4.7 \\
\hline Middle school certificate & 52 & 92 & 144 & 53.6 & 46.2 & 48.6 \\
\hline High school certificate & 14 & 56 & 70 & 14.4 & 28.1 & 23.6 \\
\hline College or university's degree & 8 & 21 & 29 & 8.2 & 10.6 & 9.8 \\
\hline Professional school graduate & 8 & 16 & 24 & 8.2 & 8.0 & 8.1 \\
\hline No formal education & 10 & 5 & 15 & 10.3 & 2.5 & 5.1 \\
\hline Total & 97 & 199 & 296 & & & \\
\hline \multicolumn{7}{|l|}{ Per capita monthly income ${ }^{*}$} \\
\hline Less than 500 Yuan & 54 & 23 & 77 & 55.7 & 12.1 & 26.8 \\
\hline
\end{tabular}


(Table 1 continued)

\begin{tabular}{lllllll}
\hline Characteristics & LH & AH & Total & LH (\%) & AH (\%) & Total (\%) \\
\hline 500-1,000 Yuan & 17 & 46 & 63 & 17.5 & 24.2 & 22.0 \\
1,000-1,500 Yuan & 12 & 57 & 69 & 12.4 & 30.0 & 24.0 \\
1,500-2,000 Yuan & 6 & 23 & 29 & 6.2 & 12.1 & 10.1 \\
More than 2,000 Yuan & 8 & 40 & 48 & 8.2 & 21.1 & 16.7 \\
Total & 97 & 190 & 287 & & & \\
\hline Health status & & & & & & \\
\hline Good & 31 & 113 & 144 & 32.0 & 56.5 & 48.5 \\
Normal & 21 & 57 & 78 & 21.6 & 28.5 & 26.3 \\
Poor & 45 & 30 & 75 & 46.4 & 15.0 & 25.3 \\
Total & 97 & 200 & 297 & & & \\
\hline
\end{tabular}

The total respondents of each characteristic may not be identical with 297 due to missing values.

* 1 RMB approximately equals 0.16 dollar.

education, with $23.6 \%$ of them graduated from middle high school. The majority (72.8\%) earned less than 1,500 Yuan per month. The income of those in low-rent housing was much lower than those of affordable housing residents, more than half (55.7\%) earned less than 500 Yuan per month. Almost half of the respondents (48.5\%) generally consider the status of their health good. Nevertheless, those in low-rent housing had converse perception of their health, $46.4 \%$ of them thought their health was poor. In general, affordable housing residents had a relatively good financial situation and health status, there was no significant difference found in other characteristics.

\subsection{Indices of Satisfaction about Different Housing Unit Features}

Overall, in the "plus" indices of satisfaction, the number of respondents who were satisfied with housing unit features were more than those that were dissatisfied (Table 2). It is evident that the most satisfying feature for residents is the bathroom, of which the index of satisfaction reached 0.642 , followed by heating supply at 0.588 , and kitchen at 0.534 . Relatively, residents were not so satisfied with the living room as compared to other housing unit features. In the comparative indices of satisfaction with the low-rent housing and the affordable housing, significant differences could be found on "housing unit size”, “ventilation”, “lighting”, "heating supply” and "bedroom” (Fig. 1). Except on "heating supply”, all unit features of affordable housing had similar or higher level of satisfaction, compared with the low-rent housing, which indicated a better living environment.

Table 2 Indices of satisfaction about different housing unit features.

\begin{tabular}{llllllll}
\hline Housing unit features & $S_{(\mathrm{LH})}$ & $D_{(\mathrm{LH})}$ & $Y I S_{(\mathrm{LH})}$ & $S_{(\mathrm{AH})}$ & $D_{(\mathrm{AH})}$ & $Y_{(\mathrm{AH})}$ & $Y I S$ \\
\hline Housing unit size & 52 & 45 & 0.072 & 144 & 56 & 0.440 & 0.320 \\
Ventilation & 55 & 42 & 0.134 & 142 & 58 & 0.420 & 0.327 \\
Lighting & 63 & 34 & 0.299 & 162 & 38 & 0.620 & 0.515 \\
Heating supply & 79 & 12 & 0.736 & 141 & 45 & 0.516 & 0.588 \\
Floor plan & 65 & 32 & 0.340 & 132 & 67 & 0.327 & 0.331 \\
Bedroom & 64 & 33 & 0.320 & 158 & 42 & 0.580 & 0.495 \\
Living room & 60 & 36 & 0.250 & 120 & 79 & 0.206 & 0.220 \\
Kitchen & 71 & 26 & 0.464 & 156 & 43 & 0.568 & 0.534 \\
Bathroom & 80 & 16 & 0.667 & 163 & 37 & 0.630 & 0.642 \\
Overall & 70 & 27 & 0.443 & 158 & 42 & 0.580 & 0.535 \\
\hline
\end{tabular}

$S=$ Satisfied D $=$ Dissatisfied. 


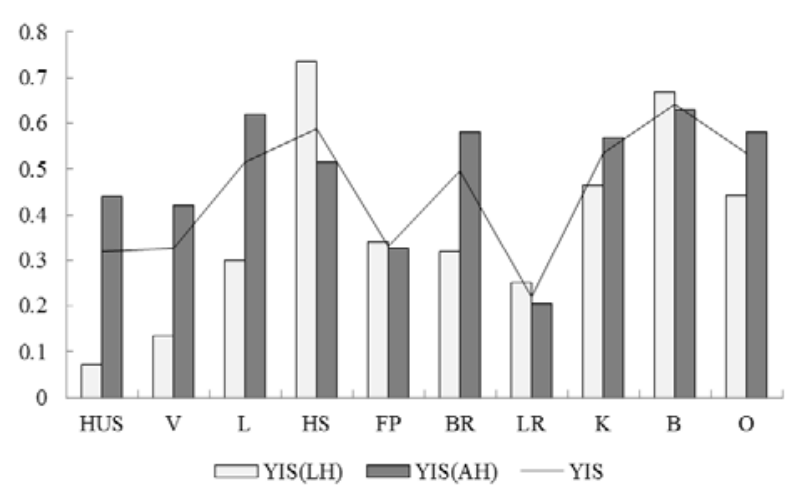

Fig. 1 Comparison of indices of satisfaction about different housing unit features between affordable housing and low-rent housing (HUS-housing unit size; V-ventilation; L-lighting; HS-heating supply; FP-floor plan; BR-bedroom; LR-living room; K-kitchen; B-bathroom; O-overall satisfaction with housing unit features).

\subsection{Housing Unit Size}

The satisfaction index on housing unit size in the low-rent is much lower than in the affordable housing. This is probably caused by the current local regulations, in which the housing unit sizes of both types are strictly limited to $70 \mathrm{~m}^{2}$ and $50 \mathrm{~m}^{2}$ in floor space respectively. Furthermore, the qualification to access the public housing is determined based on one's income, while family size and type were not taken into consideration. Consequently, no matter how large one's household is, the size of public housing is fixed. For some large families in the low-rent housing, it is evident that the housing size is inadequate thus shows a deep dissatisfaction.

\subsection{Ventilation}

Ventilation is an important factor which could also affect residents comfort. The data revealed that ventilation in low-rent housing was considered worse than that in affordable housing residents. Bathroom ventilation was bad since no artificial appliances were available to improve the foul air, which is partly blamed on the cheap construction cost as is strictly controlled by the government. Unlike affordable housing, investment in low-rent housing construction is from the central and local government coffers. Thus, local governments prefer limiting investment in public housing construction to save money that can be invested in other profitable sectors, like commercial housing development.

\subsection{Lighting}

According to residents, bad lighting was one of the most important factors for remodeling, especially the lighting in living room. Residents desired natural lighting into the living room. In order to fulfill this, residents create windows in the inner walls, a behavior which is both dangerous and hazardous to the residents' safety and health. Similar with ventilation, the lighting in low-rent housing was seen very poor by residents, as those of affordable housing type.

\subsection{Heating Supply}

Shenyang is a typical winter city, of which the average temperature is around $-11.1{ }^{\circ} \mathrm{C}$ (2011). Heating supply therefore is vital for residents in winter season. Though it has not been discussed as a component of housing unit in the previous studies. The data revealed that heating supply has a relatively high satisfaction level in the assessed features. The low-rent housing residents were more satisfied than those at affordable housing. In fact, the heating condition fulfilled residents' desire for comfortable warm interior spaces.

\subsection{Floor Plan}

Comparatively, the floor plan had a relatively low satisfaction level from both low-rent housing and affordable housing residents. The diversity of family types and sizes caused various space demands and needs, which the current floor plan types hardly fulfilled their demands or desire. Furthermore, the public housing distribution system, which did not take the applicants' family type and size into consideration, is another significant cause for this situation. Consequently, remodeling becomes very common in 
housing typologies, even though it is prohibited in the housing regulations. The composition of family is also changing with new births and older people passing on. According to some residents, their poor health had led their incapability to work and could not earn enough for their special needs. Consequently, they have no choice but to live in the public housing for a relatively long period of time. The changing family composition therefore should be taken into account by both the architects and policy makers as an important point in the floor plans.

\subsection{Bedroom}

There is a significant difference found between the bedrooms of low-rent housing and affordable housing residents. The number of bedrooms is the issue at stake. Based on our investigation, many of the families (43.3\%) in low-rent housing had three or more family members within the one bedroom housing type, under the current local regulations (50 $\mathrm{m}^{2}$ maximum). As a result, the incongruity between demands and supply caused the low satisfaction level. However, the number of bedrooms in affordable housing generally satisfied the demands of residents, therefore had a higher satisfaction level.

\subsection{Living Room}

Zhou and Wang [21] argued that the more family member one household has, the wider living room it prefers in Chinese public housing. Most families (57.2\%) interviewed had three members or more, which implied the need for a wider living room to guarantee a more satisfying space. Currently, the living room in public housing apparently did not satisfy the part on residents' needs, thus obtained a relatively low satisfaction. This supports the notion of Zhou and Wang to some extent. In some big families, the living room also functioned as a temporary place for sleeping or dining. The diversity of living room usage requires more space which is difficult to achieve in the context of current strict regulations on housing size.

\subsection{Kitchen and Bathroom}

Generally, the residents were satisfied with the kitchen and bathroom in both the low-rent and affordable housing. The differences of YIS in kitchen and bathroom between the two were slight. Nevertheless, from the architects' perspective, the environment in the kitchen and bathroom were unsatisfactory, which supports the residents' dissatisfaction, though they just inclined to say as satisfying. This revealed the residents having a high tolerance to foul spatial environment, as compared to the bedroom and living room.

\subsection{Correlation Analyses}

The correlation between overall satisfaction with housing unit and other single unit feature was evaluated and compiled into Table 3 . The higher the correlation coefficient, the closer correlation the features have with residents' overall satisfaction with housing unit. The results indicated that the living room has the highest correlation $(r=0.562)$ with residents' overall satisfaction, followed by floor plan $(r=0.498)$ and kitchen $(r=0.485)$. Consequently, the living room has high positive correlation with the residents' satisfaction of housing unit. Meanwhile, the correlation coefficient of living room and floor plan which also exceeded 0.5 , revealed a high positive correlation as well. It imported the living room played an important role in the process of assessment. According to the residents' subjective comments, the inadequate space and bad lighting were the main factors to determine satisfaction. In Fig. 2, X-axis and Y-axis respectively stand for YIS and Pearson correlation coefficients. Spots located in the second quadrant indicate that these features have relatively low satisfaction level while a high correlation with residents' overall satisfaction with housing unit. Thus, improving living room, floor plan, housing unit size and ventilation may positively affect residents' satisfaction and should be paid special attention to. 
Table 3 Correlation coefficient of each single feature with overall housing unit features satisfaction.

\begin{tabular}{|c|c|c|c|c|c|c|c|c|c|c|}
\hline & HUS & $\mathrm{V}$ & $\mathrm{L}$ & HS & $\mathrm{FP}$ & $\mathrm{BR}$ & LR & $\mathrm{K}$ & B & $\mathrm{O}$ \\
\hline HUS & 1 & & & & & & & & & \\
\hline V & $0.430^{* *}$ & 1 & & & & & & & & \\
\hline $\mathrm{L}$ & $0.307^{* *}$ & $0.398^{* *}$ & 1 & & & & & & & \\
\hline HS & $0.130^{*}$ & 0.101 & $0.273^{* *}$ & 1 & & & & & & \\
\hline FP & $0.424^{* *}$ & $0.360^{* *}$ & $0.298^{* *}$ & $0.168^{* *}$ & 1 & & & & & \\
\hline BR & $0.418^{* *}$ & $0.304^{* *}$ & $0.270^{* *}$ & $0.272^{* *}$ & $0.414^{* *}$ & 1 & & & & \\
\hline LR & $0.395^{* *}$ & $0.353^{* *}$ & $0.289^{* *}$ & $0.190^{* *}$ & $0.547^{* *}$ & $0.486^{* *}$ & 1 & & & \\
\hline K & $0.301^{* *}$ & $0.375^{* *}$ & $0.284^{* *}$ & $0.189^{* *}$ & $0.482^{* *}$ & $0.491^{* *}$ & $0.508^{* *}$ & 1 & & \\
\hline B & $0.279^{* *}$ & $0.288^{* *}$ & $0.218^{* *}$ & $0.289^{* *}$ & $0.298^{* *}$ & $0.414^{* *}$ & $0.373^{* *}$ & $0.470^{* *}$ & 1 & \\
\hline $\mathrm{O}$ & $0.468^{* *}$ & $0.410^{* *}$ & $0.348^{* *}$ & $0.305^{* *}$ & $0.498^{* *}$ & $0.480^{* *}$ & $0.562^{* *}$ & $0.485^{* *}$ & $0.408^{* *}$ & 1 \\
\hline
\end{tabular}

** Correlation is significant at the 0.01 level (2-tailed). $\quad$ *Correlation is significant at the 0.05 level (2-tailed).

HUS—housing unit size; V—ventilation; L-lighting; HS—heating supply; FP—floor plan; BR—bedroom; LR—living room; $\mathrm{K}$-kitchen; B-bathroom; O_overall satisfaction with housing unit features.

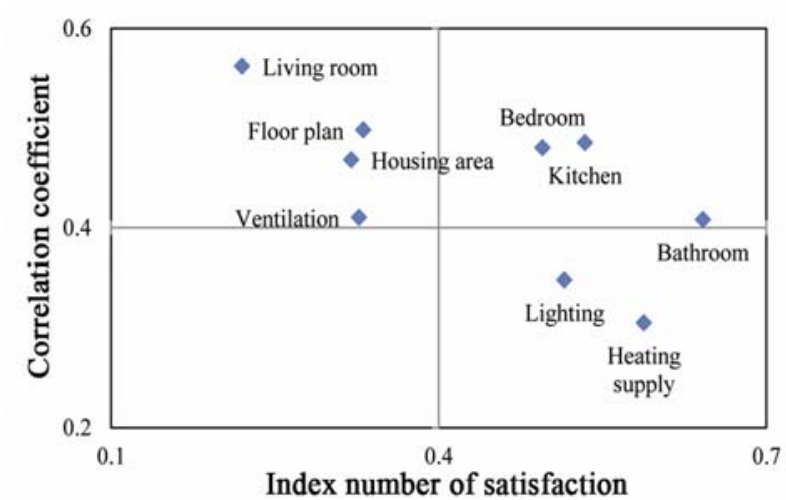

Fig. 2 The priority of improvement to satisfy more public housing residents.

\section{Conclusions and Policy and Design Implications}

In general, the affordable housing residents were more satisfied with housing unit features than the low-rent housing residents. The most dissatisfying features were the living room, followed by housing area and floor plan. In the low-rent housing residents, current public housing failed in providing them with enough bedrooms which was a major reason for the low satisfaction. In contrast with the low-rent housing residents, affordable housing residents inclined to pay more attention on living room and floor plan. Space for family activities had become their focal concern instead of the number of bedrooms. The analysis revealed that the living room had a high positive correlation with the residents' overall satisfaction on housing unit features, followed by floor plan and kitchen. Briefly, improving the living room, floor plan, housing area and ventilation are more effective and efficient ways to alleviate residents' dissatisfaction on their housing units.

The housing unit features were usually estimated as a single variable in other relevant studies on residential satisfaction from Chinese scholars [11, 12]. But, this study discusses and tries to determine how each unit feature correlates with the overall satisfaction. As discussed in the previous section, this will play an important role for architects in public housing design and building remodeling practices. Moreover, the findings are also valuable for detailed policy and design code making.

The study reveals that the inadequate housing unit size was an important reason for low-rent housing residents' low satisfaction on housing unit features. Related studies also found the positive correlation between housing unit size and residential satisfaction $[23,24]$. These studies imported that current local regulations, in which the housing area of low-rent housing is restricted into $50 \mathrm{~m}^{2}$, pressingly need some modifications. Policy makers should take family type and size into consideration and provide more diverse housing unit to satisfy different families. Additionally, ventilation was also highly correlated with residents' satisfaction which obtained a low satisfaction, thus 
deserves improvements. Notwithstanding a limited construction budget, necessary artificial appliances should not be ignored, which is particularly helpful to improve residents' satisfaction in the housing unit features. Relatively, affordable housing residents are satisfied with the housing size (limited into $70 \mathrm{~m}^{2}$ ) and the number of bedrooms (usually two bedrooms). Generally, the low-rent housing, which target the lowest stratum of social income, should attract more attention from policy makers.

Public housing designer should pay more attention on living room design and floor plan. Residents demand a wider living room to support their diverse family activities, such as dining, temporary sleeping and family meeting. Zhou and Long [20], in their study of daily life on behavior of low-rent housing residents, argued that if the gross housing area is fixed, the living room should be wider. In 2009, Zhou also found that big size families (three family members or more) prefer wider living room to wider bedroom [21]. Additionally, our study indicates living room is highly and positively correlated with residents' overall satisfaction with housing unit features while obtained a low satisfaction. All these studies demonstrate that improving the size and quality of living room would considerably increase the residents' satisfaction. Floor plan is another important factor affecting residents' satisfaction. To fulfill their special demands on unit spaces, many residents remodeled the original floor plan, which may cause an increase in family expenditure, when a new family moves in. Consequently, a flexible floor plan which enables residents to do some subtle changes on floor plan may be preferred.

Nowadays, China is experiencing a large-scale public housing construction process. Alleviating the shortage of public housing provision has become a focus of Chinese public policies. Intensive construction is supposed to achieve this aim in a relatively short period of time. Nevertheless, it does not mean we would never suffer new problems of public housing in the future. How to substantially improve residential satisfaction of public housing should be as important as the public housing provision in quantitative terms. This is the question which should be seriously considered by both the policy makers and building designers.

\section{Acknowledgments}

The authors gratefully acknowledge the students from Northeastern University in China for their assistance in the questionnaire survey and anonymous reviewers for their valuable advice and comments.

\section{References}

[1] J. Chen, F. Guo, Y. Wu, One decade of urban housing reform in China: Urban housing price dynamics and the role of migration and urbanization, 1995-2005, Habitat International 35 (2011) 1-8.

[2] Y.P. Wang, Urban housing reform and finance in China: A case study of Beijing, Urban Affairs Review 36 (5) (2001) 620-645.

[3] C. Wang, Economical and comfortable house: Its historical role and future direction of reform, Finance \& Trade Economics 11 (2003) 70-74. (in Chinese)

[4] Z. Huang, The effect analysis of affordable housing policies, Economic Science 3 (2004) 92-101. (in Chinese)

[5] X. Ping, M. Chen, Real estate financing, the price of land and the trend of housing price, The Journal of World Economy 7 (2004) 3-10. (in Chinese)

[6] P. Li, Residential satisfaction on affordable housing and its determinants-Evidence from a housing survey in Beijing, South China Journal of Economics 4 (2010) 15-36. (in Chinese)

[7] Y. Ge, C. Jia, The facts and roots of insufficient supply of low-rent housing-Analysis based on the perspective of the behaviors of Chinese local governments during the transition period, Economist 8 (2011) 27-35. (in Chinese).

[8] K. Jia, J. Liu, A study on Chinese housing reform and housing security, Public Finance Research 7 (2007) 8-23. (in Chinese)

[9] Y. Liu, Analyses related to public rental housing —-Based on local governments' practice, Qinghai Social Science 1 (2012) 77-82. (in Chinese)

[10] V.N. Shaw, Urban housing reform in China, Habitat International 2 (2) (1997) 199-212.

[11] Y. Fang, Residential satisfaction, moving intention and moving behaviors: A study of redeveloped neighborhoods in inner-city Beijing, Housing Studies 
21(5) (2006) 671-694.

[12] S. Li, Y. Song, Redevelopment, displacement, housing conditions and residential satisfaction: A study of Shanghai, Environment and Planning 41 (2009) 1090-1108.

[13] X. Ma, Q. Yuan, Research advances in public housing policies and urban spaces, Architectural Journal 8 (2011) 55-59. (in Chinese)

[14] D.P. Varady, M.A. Carrozza, Towards a better way to measure customer satisfaction levels in public housing: A Report from Cincinnati, Housing Studies 16 (6) (2000) 797-825.

[15] J. Kinsey, S. Lane, Race, housing attributes, and satisfaction with housing, Housing and Society 10 (1983) 98-116.

[16] M. Lu, Determinants of residential satisfaction: Ordered logitvs regression models, Growth and Change 30 (1999) 264-287.

[17] M.A. Mohit, M. Ibrahim, Y.R. Rashid, Assessment of residential satisfaction in newly designed public low-cost housing in Kuala Lumpur, Malaysia, Habitat International 34 (2010) 18-27.

[18] E. Vera-Toscano, V. Ateca-Amestoy, The relevance of social interactions on housing satisfaction, Soc. Indic. Res. 86 (2008) 257-274.

[19] A.G. Salleh, Neighborhood factors in private low-cost housing in Malaysia, Habitat International 32 (2008) 485-493.

[20] X. Zhou, T. Long, Study on the daily life behavior of low-income families in Shanghai, Architectural Journal 8 (2009) 10-13. (in Chinese)

[21] Y. Zhou, F. Wang, A Study on residential needs of low-income group in Beijing and its design implications, Architectural Journal 8 (2009) 6-9. (in Chinese)

[22] J.D. Smyth, D.A. Dillman, L.M. Christan, M.J. Stern, Comparing checked-all and force-choice question formats in web surveys, Public Opinion Quarterly 70 (1) (2006) 66-77.

[23] D.P. Varady, W.F.E. Preiser, Scattered-site public housing and housing satisfaction-Implications for the new public housing program, Journal of the American Planning Association 64 (1998) 189-207.

[24] S. Kaitilla, Satisfaction with public-housing in Papua New Guinea-The case of West Taraka housing scheme, Environment and Behavior 25 (1993) 514-545. 